\title{
FINANSAL BAŞARISIZLIK VE İSTATISTIKSEL YÖNTEMLER: BORSA İSTANBUL UYGULAMASI
}

Seda ABACIOĞLU

Elif BULUT 


\section{(C) Copyright 2020}

Bu kitabın, basım, yayın ve satış haklarn Akademisyen Kitabevi A.Ş.'ne aittir. Anılan kuruluşun izni alınmadan kitabın tümü ya da bölümleri mekanik, elektronik, fotokopi, manyetik kağıt ve/veya başka yöntemlerle çoğaltılamaz, basılamaz, dağıtılamaz. Tablo, şekil ve grafikler izin alınmadan, ticari amaçh kullanılamaz. Bu kitap T.C. Kültür Bakanlğ̆ bandrolü ile satılmaktadır.

\section{ISBN}

978-625-7795-21-0

\section{Kitap Adı}

Finansal Başarısızlık ve İstatistiksel Yöntemler:

Borsa İstanbul Uygulaması

\section{Yazarlar}

Arş. Gör. Seda ABACIOĞLU

ORCID iD: 0000-0002-3150-2770

Dr. Elif BULUT

ORCID iD: 0000-0001-8278-1821

Ondokuz Mayıs Üniversitesi İktisadi ve İdari Bilimler Fakültesi İşletme Bölümü

\section{Yayın Koordinatörü}

Yasin Dilmen

Sayfa ve Kapak Tasarımı

Akademisyen Dizgi Ünitesi

\section{Yayıncı Sertifika No}

47518

\section{Baskı ve Cilt}

Bisac Code

BUS027000

\section{GENEL DAĞITIM}

\section{Akademisyen Kitabevi A.Ș.}

Halk Sokak 5 / A

Yenişehir / Ankara

Tel: o312 4311633

siparis@akademisyen.com 


\section{İCINDEKILER}

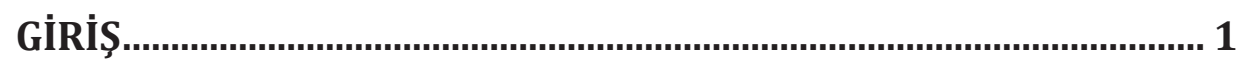

\section{BÖLÜM}

\section{FİNANSAL BAŞARISIZLIK KAVRAMI}

1.1. İşletmelerde Başarısızlık Kavramı........................................................................... 5

1.2. İşletmelerde Başarısızlık Türleri ...............................................................................

1.2.1. Ekonomik Başarısılzlk ...................................................................................

1.2.2. Finansal Başarısızlık....................................................................................

1.2.2.1. Finansal Başarısızlık Durumları ........................................................11

1.2.2.1.1. Kârın Sürekli Olarak Düşük veya Negatif Çıkması......................11

1.2.2.1.2. İşletmenin Teknik Likiditesini Kaybetmesi....................................12

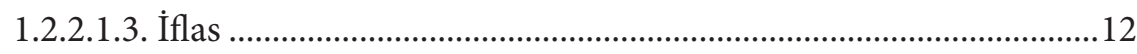

1.2.2.2. Finansal Başarısızlığın Nedenleri ....................................................12

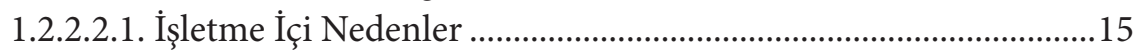

1.2.2.2.1.1. Yanlı̧ Yönetim ..............................................................................15

1.2.2.2.1.2. Düşük Likidite ...........................................................................17

1.2.2.2.1.3. Yetersiz İşletme Sermayesi.............................................................. 17

1.2.2.2.1.4. İşletmenin Yaşam Döngüsü..........................................................17

1.2.2.2.2. İşletme Diş1 Nedenler...........................................................................19

1.2.2.2.2.1. Toplumsal Çevre...........................................................................19

1.2.2.2.2.2. Ekonomik Çevre .....................................................................20

1.2.2.2.2.3. Hukuki ve Politik Çevre................................................................20

1.2.2.2.2.4. Doğal Çevre....................................................................................21

1.2.2.3. Finansal Başarısızlığa Karşı Alınabilecek Önlemler ........................21

1.2.2.3.1. Sermaye Yapısının Güçlendirilmesi veya

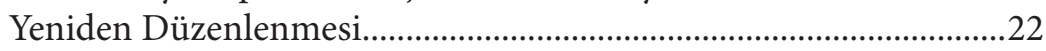

1.2.2.3.1.1. Sermaye Artırımı.........................................................................23

1.2.2.3.1.2. Borçlara Karşılık Olarak Hisse Senedi veya

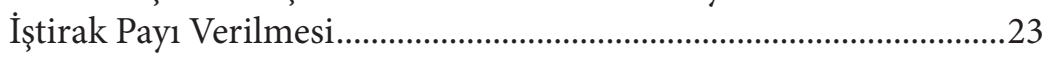

1.2.2.3.1.3. Tahvil Faizlerinin Düşürülmesi ...................................................23

1.2.2.3.1.4. Tahvillerin Kâra İștirakli Tahvillerle Değiştirilmesi...................23

1.2.2.3.1.5. İmtiyazlı Hisse Senetlerinin Adi Hisse

Senetleri ile Değiştirilmesi....................................................................23

1.2.2.3.1.6. Hisse Senetlerinin Nominal Değerlerinin Düşürülmesi .........24

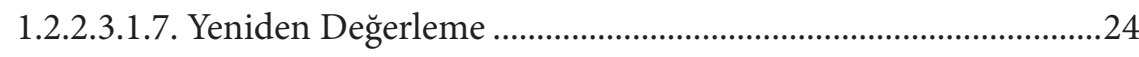


1.2.2.3.2. Borçların Vadesinin Uzatılması ...................................................24

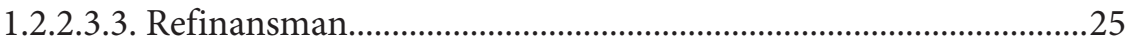

1.2.2.3.4. Alacaklıların Alacaklarından Vazgeçmesi....................................25

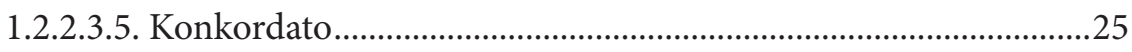

1.2.2.3.6. İşletmede Kullanılmayan Varlıkların Satılması ...........................26

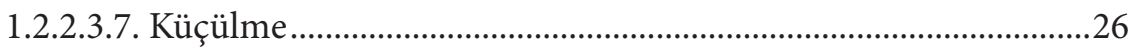

1.2.2.3.8. Yeni İşletmeler ile Ortaklık Yapılması..........................................26

1.2.2.3.9. Borçların Öz Kaynağa Çevrilmesi ...............................................26

1.2.2.3.10. İşletmenin Hukuki Şeklinin Değiştirilmesi ...............................27

1.2.2.3.11. İşletmenin Alacaklılarının Temsilcilerinden Oluşan Bir Komite Tarafından Yönetilmesi ....................................................................27

1.2.2.3.12. İşletmenin Faaliyetlerine Son Verme veya İşletmeyi Satma ....27

1.2.2.4. Finansal Başarısızlığın Sonuçları...................................................28

1.2.2.4.1. Teknik Likidite Kaybı .................................................................28

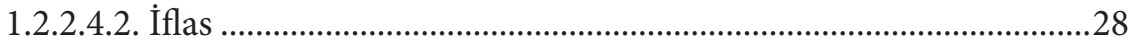

\section{BÖLÜM}

\section{LITERATÜR TARAMASI}

2.1. Türkiye’de Finansal Başarısızlıkla İlgili Yapılmış Çalışmalar...........................31

2.2. Yurt Dışında Finansal Başarısızlıkla İlgili Yapılmış Çalışmalar......................40

\section{BÖLÜM}

\section{FINAANSAL BAŞARISIZLIĞI BELİRLEMEDE FINANSAL ORANLARIN KULLANILMASI}

3.1. Finansal Tablolar

3.2. Finansal Başarısızlığı Belirlemede Finansal Tablolardan Elde Edilen Finansal Oranlar.

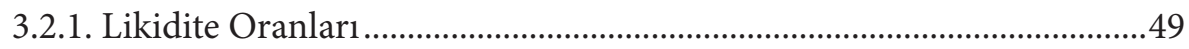

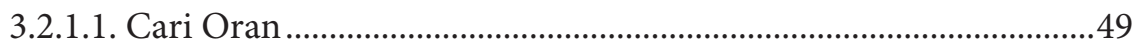

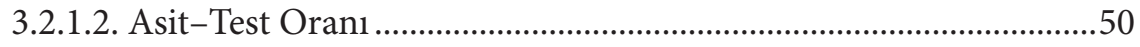

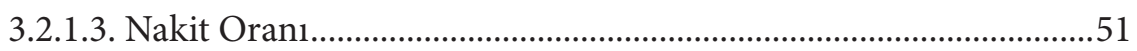

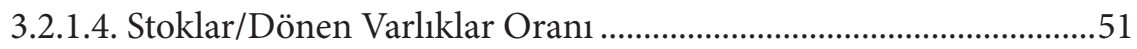

3.2.1.5. Stoklar/Toplam Varlıklar Oran1 .......................................................51

3.2.1.6. Stok Bağımlılık Oranı.........................................................................52

3.2.1.7. Kısa Vadeli Ticari Alacaklar/Toplam Varlıklar Oranı.....................52

3.2.1.8. Kısa Vadeli Ticari Alacaklar/Dönen Varlıklar Oranı......................5 52

3.2.1.9. Net Çalışma Sermayesi/Toplam Varlıklar Oranı ............................53

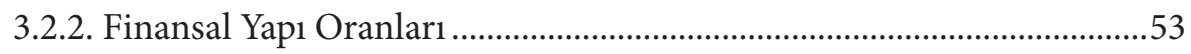

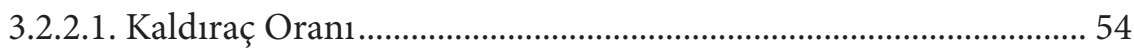




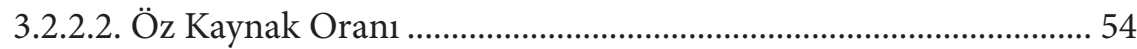

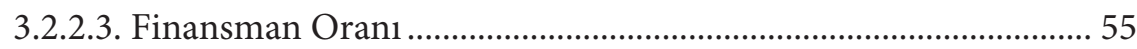

3.2.2.4. Kısa Vadeli Yabancı Kaynaklar/Toplam Borçlar Oran1................. 55

3.2.2.5. K1sa Vadeli Yabanc1 Kaynaklar/Toplam Kaynaklar Oranı............ 56

3.2.2.6. Uzun Vadeli Yabancı Kaynaklar/Toplam Kaynaklar Oran1......... 56

3.2.2.7. Duran Varlıklar/Öz Kaynaklar Oranı............................................... 56

3.2.2.8. Duran Varlıklar/Devamlı Sermaye Oran1........................................ 56

3.2.2.9. Devamlı Sermayenin Bağımlılı̆̆ Oranı.......................................... 57

3.2.2.10. Maddi Duran Varlıklar/Öz Kaynaklar Oranı............................... 57

3.2.2.11. Maddi Duran Varlıklar/Uzun Vadeli Yabancı Kaynaklar Oranı57

3.2.2.12. Maddi Duran Varlıklar/Toplam Varlıklar Oranı ......................... 58

3.2.2.13. Dönen Varlıklar/Toplam Varlıklar Oranı ..................................... 58

3.2.2.14. Duran Varlıklar/Toplam Varlıklar Oran1...................................... 58

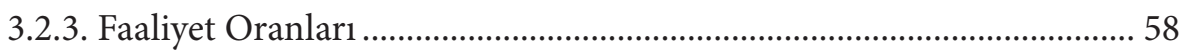

3.2.3.1. Alacak Devir Hiz1........................................................................ 59

3.2.3.2. Stok Devir Hiz1............................................................................ 59

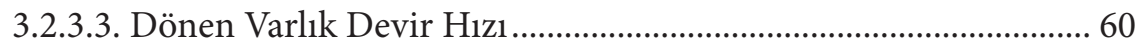

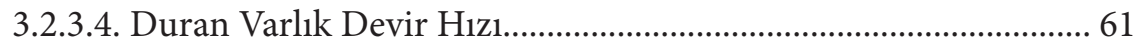

3.2.3.5. Maddi Duran Varlık Devir Hızı ....................................................... 62

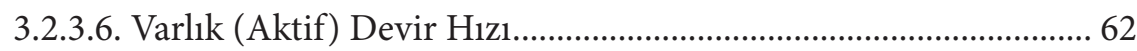

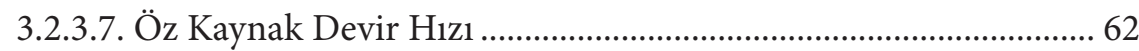

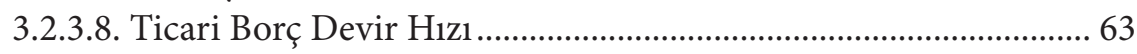

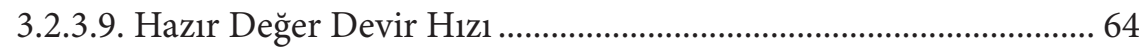

3.2.3.10. Net Çalışma Sermayesi Devir Hızı ................................................. 64

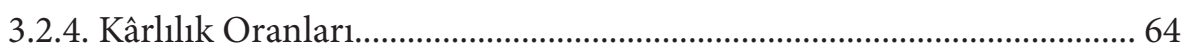

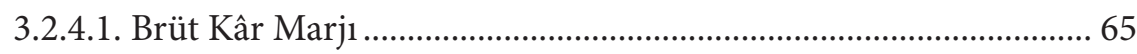

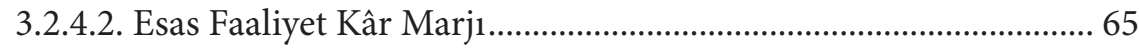

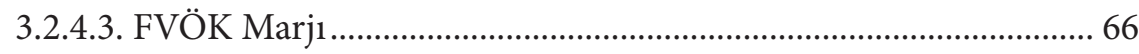

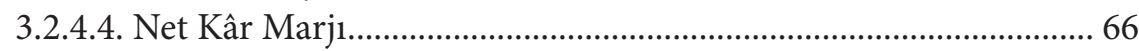

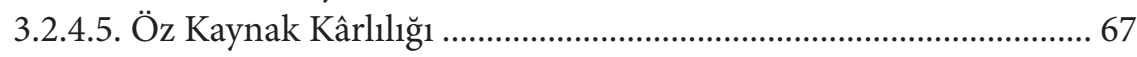

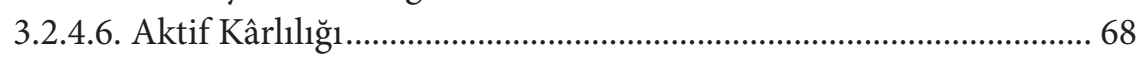

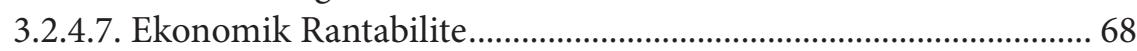

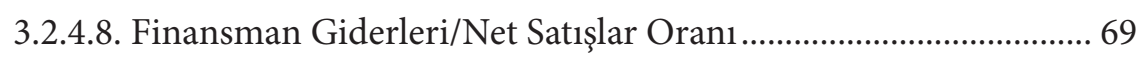

3.2.4.9. Faiz Karşılama Oran1...................................................................... 69

3.3. Finansal Başarısızlığı Belirlemede Finansal Oranları Kullanmanın

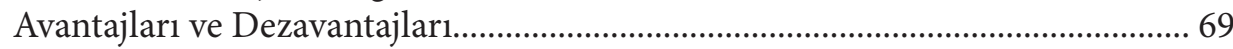

3.3.1. Finansal Başarısızlığı Belirlemede Finansal Oranları Kullanmanın Avantajlar1. 69

3.3.2. Finansal Başarısızlığı Belirlemede Finansal Oranları Kullanmanın Dezavantajları. 70 


\section{BÖLÜM \\ FINANSAL BAŞARISIZLIĞI BELİRLEMEDE İSTATISTIIKSEL YÖNTEMLERIN KULLANILMASI}

4.1. Finansal Başarısızlığı Belirlemede Kullanılan İstatistiksel Yöntemler ...........73

4.1.1. Değişken Sayısına Göre İstatistiksel Yöntemler .......................................73

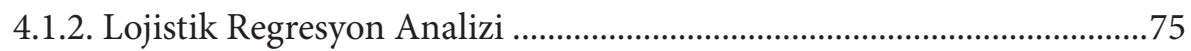

4.1.3. Kısmi En Küçük Kareler Diskriminant Analizi (KEKKDA) .................80

4.1.3.1. Kısmi En Küçük Kareler Regresyon Analizi (KEKKRA) ..............81

4.1.3.2. Kısmi En Küçük Kareler Diskriminant Analizi (KEKKDA) ........84

4.2. Finansal Başarısızlığı Belirlemede Kullanılan

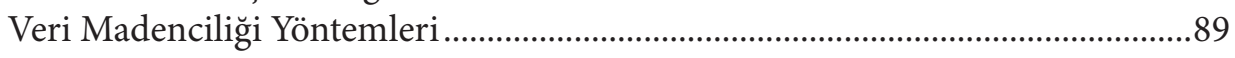

4.2.1. Karar Ağacı Analizi .................................................................................92

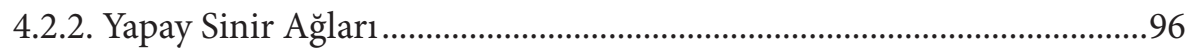

4.2.2.1. Yapay Sinir Ağlarının Tanımı........................................................96

4.2.2.2. Yapay Sinir Hücresi....................................................................97

4.2.2.2.1. Girdiler .........................................................................................98

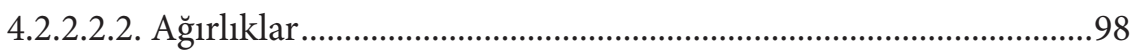

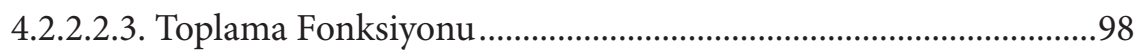

4.2.2.2.4. Aktivasyon (Etkinlik) Fonksiyonu ...............................................99

4.2.2.2.5. Hücrenin Çıktısı ........................................................................99

4.2.2.3. Yapay Sinir Ağının Yapısı...............................................................100

4.2.2.4. Yapay Sinir Ağlarında Öğrenme, Adaptif
Öğrenme ve Test Etme

4.2.2.5. Nöronlar Arası Bağlantı Yapılarına Göre Yapay Sinir Ağları......101

4.2.2.5.1. İleri Beslemeli Yapay Sinir Ağları ...............................................101

4.2.2.5.2. Geri Beslemeli Yapay Sinir Ağları ..............................................102

4.2.2.6. Katman Sayılarına Göre Yapay Sinir Ağları ..................................103

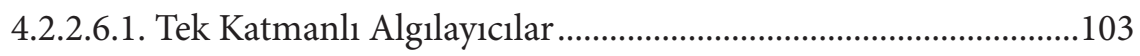

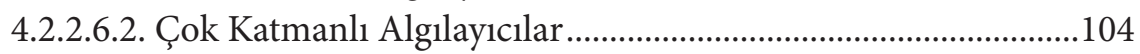

4.2.2.7. Yapay Sinir Ağlarının Genel Özellikleri .........................................104

4.2.2.8. Yapay Sinir Ağlarının Dezavantajları ...........................................105

4.2.2.9. Yapay Sinir Ağlarının Uygulama Alanları ...................................105 


\section{BÖLÜM}

\section{FİNANSAL BAŞARISIZLIĞI BELİRLEMEDE İSTATISTIIKSEL YÖNTEMLERIN SINIFLANDIRMA PERFORMANSLARININ KARŞILAŞTIRILMASI}

5.1. Araştırmanın Problemi, Amacı, Sınırlılıkları ve Modeli...............................107

5.1.1. Araştırmanın Problemi ve Amacı ...........................................................107

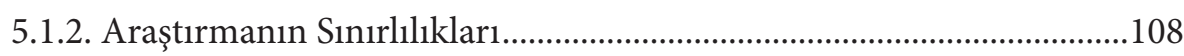

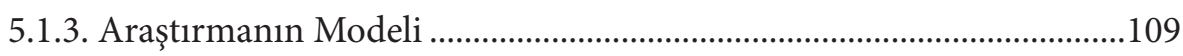

5.2. Veri Seti, Veri Toplama Aracı, Yöntemi ve Analiz Teknikleri .......................111

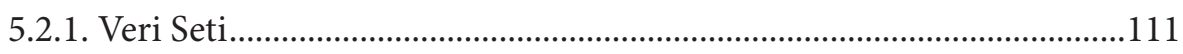

5.2.2. Veri Toplama Aracı ve Veri Toplama Yöntemi ........................................112

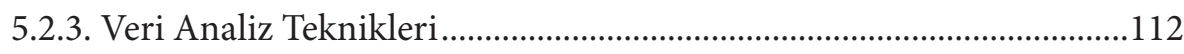

5.3. Finansal Başarısızlığın Belirlenmesinde İstatistiksel

Yöntemlerin Uygulanması.........................................................................112

5.3.1. Lojistik Regresyon Analizi Sonuçlar1.......................................................112

5.3.1.1. 1 Yıl Önceden Finansal Başarısızlı̆̆ı Belirlemeye Yönelik Lojistik Regresyon Analizi Sonuçları...........................................................113

5.3.1.2. 2 Yıl Önceden Finansal Başarısızlı̆̆ı Belirlemeye Yönelik Lojistik

Regresyon Analizi Sonuçları..........................................................117

5.3.1.3. 3 Yıl Önceden Finansal Başarısızlığı Belirlemeye Yönelik Lojistik

Regresyon Analizi Sonuçları............................................................121

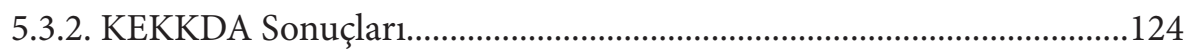

5.3.2.1. 1 Yıl Önceden Finansal Başarısızlığ Belirlemeye Yönelik

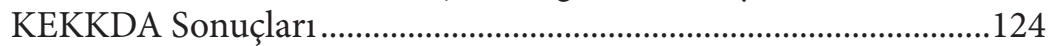

5.3.2.2. 2 Yıl Önceden Finansal Başarısızlığı Belirlemeye Yönelik KEKKDA Sonuçları.......................................................................129

5.3.2.3. 3 Yıl Önceden Finansal Başarısızlığı Belirlemeye Yönelik KEKKDA Sonuçları

5.4. Finansal Başarısızlığın Belirlenmesinde Veri Madenciliği Yöntemlerinin

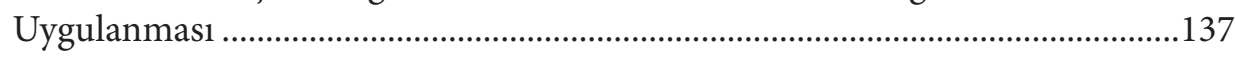

5.4.1. CHAID Analizi Sonuçları ......................................................................137

4.1.1. 1 Yıl Önceden Finansal Başarısızlığı Belirlemeye

Yönelik CHAID Analizi Sonuçları ...............................................................138

5.4.1.2. 2 Yıl Önceden Finansal Başarısızlı̆̆ı Belirlemeye

Yönelik CHAID Analizi Sonuçları..................................................142

5.4.1.3. 3 Yıl Önceden Finansal Başarısızlı̆̆ı Belirlemeye Yönelik CHAID

Analizi Sonuçları...........................................................................147 
5.4.2. Yapay Sinir Ağları Sonuçları .151

5.4.2.1. 1 Y1l Önceden Finansal Başarısızlığı Belirlemeye Yönelik Yapay Sinir Ağları Sonuçları

5.4.2.2. 2 Yıl Önceden Finansal Başarısızlığı Belirlemeye Yönelik Yapay Sinir Ağları Sonuçları.

5.4.2.3. 3 Yıl Önceden Finansal Başarısızlı̆̆ı Belirlemeye Yönelik Yapay

Sinir Ağları Sonuçları 155

5.5. Değerlendirme .157

SONUÇ ...................................................................................... 163

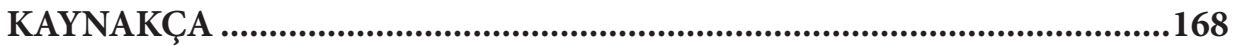




\section{KISALTMALAR}

ABD: $\quad$ Amerika Birleşik Devletleri

AID: $\quad$ Automatic Interaction Detection - Otomatik Etkileşim Belirleme Analizi

ANOVA: $\quad$ Analysis of Variance - Tek Değişkenli Varyans Analizi

BİST: Borsa İstanbul

CHAID: Chi-squared Automatic Interaction Detection - Otomatik Ki-Kare Etkileşim Belirleme Analizi

CRISP-DM: Cross Industry Standard Process for Data Mining - Çapraz Endüstri Veri Madenciliği Standart Süreci

C\&RT: $\quad$ Classification and Regression Trees - Sinıflama ve Regresyon Ağaçları

EKK: $\quad$ En Küçük Kareler

FVÖK: $\quad$ Faiz ve Vergi Öncesi Kâr

ID: $\quad$ Iterative Dichotomiser - Tekrarlı İkilikçi Ağaç

IMKB: $\quad$ İstanbul Menkul Kiymetler Borsası

KAP: $\quad$ Kamuyu Aydınlatma Platformu

KEKK: $\quad$ Kısmi En Küçük Kareler

KEKKDA: Kısmi En Küçük Kareler Diskriminant Analizi

KEKKRA: Kısmi En Küçük Kareler Regresyon Analizi

LL: $\quad$ Log Likelihood - Log Olabilirlik

MATLAB: Matrix Laboratory

NIPALS: Nonlinear Iterative Partial Least Squares

PLS: $\quad$ Partial Least Squares

PLS1: $\quad$ Bir Bağımlı Değişkenli Kısmi En Küçük Kareler

PLS2: $\quad$ Çok Sayıda Bağımlı Değişkenli Kısmi En Küçük Kareler

QUEST: Quick, Unbiased, Efficient Statistical Trees - Hızl, Yansız, Etkili İstatistiksel Ağaçlar

sd: $\quad$ Serbestlik Derecesi

SPK: $\quad$ Sermaye Piyasası Kurulu

SPSS: $\quad$ Statistical Package for the Social Sciences

TDMS: $\quad$ Tek Düzen Muhasebe Sistemi

TFRS: $\quad$ Türkiye Finansal Raporlama Standartları

TMS: $\quad$ Türkiye Muhasebe Standartları

TMSF: $\quad$ Tasarruf Mevduatı Sigorta Fonu

UFRS: $\quad$ Uluslararası Finansal Raporlama Standartları 
- 


\section{KAYNAKÇA}

Akdoğan, N. ve Tenker, N. (1992). Finansal tablolar ve mali analiz teknikleri. 4. Bask1, Ankara: Gazi Üniversitesi Basın-Yayın Yüksekokulu Matbaası.

Akdoğan, N. (2013). Finansal Tablolar Analiz Teknikleri. https://slideplayer.biz.tr/ slide/2637576, Erişim Tarihi: 17.04.2018.

Akgüç, Ö. (1998). Finansal yönetim. 7. Baskı, İstanbul: Avcıol Basım Yayın.

Akgüç, Ö. (2011). Mali tablolar analizi. 14. Baskı, İstanbul: Avcılol Basım Yayın.

Akgüç, Ö. (2013). Finansal yönetim. 8. Baskı, İstanbul: Avcıol Basım Yayın.

Akkaya G.C., Demireli E. ve Yakut Ü.H. (2009). "İşletmelerde finansal başarısızlık tahminlemesi: yapay sinir ağları modeli ile İMKB üzerine bir uygulama”. Eskişehir Osmangazi Üniversitesi Sosyal Bilimler Dergisi. 10 (2), 187-216.

Akpınar H. (2000). "Veri tabanlarında bilgi keşfi ve veri madenciliğì". İstanbul Üniversitesi İsletme Fakültesi Dergisi. 29 (1), 1-22.

Akpınar, H. (2017). Data veri madenciliği veri analizi. 2. Basım, İstanbul: Papatya. Aksu, G. ve Karaman, H. (2016). “CHAID Analizi”. C.O. Güzeller (ed.). Herkes için çok değişkenli istatistik. (s.251-272). 1. Baskı, Ankara: Maya Akademi.

Aktaş C. ve Erkuş O. (2009). "Lojistik regresyon analizi ile Eskişehir'in sis kestiriminin incelenmesi”. İstanbul Ticaret Üniversitesi Fen Bilimleri Dergisi. 8 (16), 47-59.

Aktaş, R. (1993). Endüstri işletmeleri için mali başarısızlık tahmini (çok boyutlu model uygulaması). Ankara: Türkiye İş Bankası Kültür Yayınları.

Aktaş, R. (1997). Mali başarısızlık (işletme riski) tahmin modelleri. Ankara: Türkiye İş Bankası Kültür Yayınları.

Aktaş R., Doğanay M.M. ve Yıldız B. (2003). "Mali başarısızlığın öngörülmesi: istatistiksel yöntemler ve yapay sinir ağı karşılaştırması”. Ankara Üniversitesi SBF Dergisi. 58 (4), $1-24$.

Akyüz K.C., Yıldırım İ., Akyüz İ. ve Tugay T. (2017). “Borsa İstanbul'da işlem gören kağıt ve kağıt ürünleri sanayi işletmelerinin finansal başarısızlık düzeylerinin oran analizi ve diskriminant analizi yöntemleri kullanılarak ölçümlenmesi”. Journal of Forestry. 13 (1), 60-74.

Albayrak, A.S. (2006). Uygulamalı çok değişkenli istatistik teknikleri. 1. Baskı, Ankara: Asil.

Albayrak, A.S. (2010). "Lojistik regresyon analizi". Ş. Kalaycı (ed.). SPSS uygulamalı çok değişkenli istatistik teknikleri. (s. 273-298). 5. Baskı, Ankara: Asil.

Albayrak A.S. ve Yılmaz Ş.K. (2009). "Veri madenciliği: karar ağacı algoritmaları ve İMKB verileri üzerine bir uygulama”. Süleyman Demirel Üniversitesi İktisadi ve İdari Bilimler Fakültesi Dergisi. 14 (1), 31-52.

Aliakbarzadeh G., Parastar H. \& Sereshti H. (2016). "Classification of gas chromatographic fingerprints of saffron using partial least squares discriminant analysis together with different variable selection methods". Chemometrics and Intelligent Laboratory Systems. 158, 165-173.

Alladio E., Giacomelli L., Biosa G., Corcia D.D., Gerace E., Salomone A. \& Vincenti M. (2018). "Development and validation of a partial least squares-discriminant analysis (PLS-DA) model based on the determination of ethyl glucuronide (EtG) and fatty acid ethyl esters (FAEEs) in hair for the diagnosis of chronic alcohol abuse". Forensic Science International. 282, 221-230. 
Altaş D. ve Giray S. (2005). "Mali başarısızlığın çok değişkenli istatistiksel yöntemlerle belirlenmesi: tekstil sektörü örneği”. Anadolu Üniversitesi Sosyal Bilimler Dergisi. 5 (2), 13-27.

Altman E.I. (1968). "Financial ratios, discriminant analysis and the prediction of corporate bankruptcy". The Journal of Finance. 23 (4), 589-609.

Altman E.I. \& Loris B. (1976). "A financial early warning system for over-the counter broker-dealers". The Journal of Finance. 31 (4), 1201-1217.

Altman E.I., Haldeman R.G. \& Narayanan P. (1977). "Zeta analysis: a new model to identify bankruptcy risk of corporations". Journal of Banking and Finance. 1 (1), 29-54.

Altman E.I. (1983). Corporate financial distress: a complete guide to predicting, avoiding and dealing with bankruptcy. New York: John and Wiley Sons.

Altman E.I. (2000). "Predicting financial distress of companies: revisiting the z-score and zeta models". Technical Report. Stern School of Business, New York University.

Altman E.I. \& Hotchkiss E. (2006). Corporate financial distress and bankruptcy: predict and avoid bankruptcy, analyze and invest in distressed debt. 3rd ed., New Jersey: John Wiley and Sons.

Altunkaynak, B. (2017). Veri madenciliği yöntemleri ve R uygulamaları. Ankara: Seçkin.

Altunöz U. (2013). "Bankaların finansal başarısızlıklarının yapay sinir ağları modeli çerçevesinde tahmin edilebilirliği”. Dokuz Eylül Üniversitesi İktisadi ve İdari Bilimler Fakültesi Dergisi. 28 (2), 189-217.

Altunöz U. (2015). "Lojistik regresyon ve diskriminant yöntemleriyle banka başarısızlıklarının tahmini: Türk bankaları deneyimi”. Kahramanmaraş Sütçü İmam Üniversitesi İktisadi ve İdari Bilimler Fakültesi Dergisi, 5 (1), 45-54.

Andreev, Y.A. (2005). Determinants of the decision-taking process of the entry into insolvency, evolution of the procedure and earnings management: an economic perspective of Spanish distressed companies. Doctoral dissertation, Universidad Autónoma de Barcelona Department of Business Economics, Barcelona.

Apak, S. ve Demirel, E. (2010). Finansal yönetim cilt 2. finansal tablolar analizi ve yatırım yönetimi. 1. Basım, İstanbul: Papatya Yayıncılık.

Arı A. ve Berberler M.E. (2017). "Yapay sinir ağları ile tahmin ve sınıflandırma problemlerinin çözümü için arayüz tasarımı”. Acta Infologica. 1 (2), 55-73.

Asilkan Ö. ve Irmak S. (2009). "İkinci el otomobillerin gelecekteki fiyatlarının yapay sinir ağları ile tahmin edilmesi”. Süleyman Demirel Üniversitesi İktisadi ve İdari Bilimler Fakültesi Dergisi. 14 (2), 375-391.

Ataseven B. (2013). "Yapay sinir ağları ile öngörü modellemesi”. Öneri Dergisi. 10 (39), 101-115.

Ayan T.Y. ve Değirmenci N. (2018). "Firma finansal başarısızlık öngörüsü için bir lojistik regresyon modeli”. Uluslararası İktisadi ve İdari İncelemeler Dergisi. 18. EYİ Özel Sayıs1, 77-88.

Aydın, N., Başar, M. ve Coşkun M. (2010). Finansal yönetim. 1. Baskı, Ankara: Detay Yayıncilik.

Aygören H., Sarıtaş H. ve Moralı T. (2012). "İMKB 100 endeksinin yapay sinir ağları ve Newton nümerik arama modelleri ile tahmini”. Uluslararası Alanya Işsletme Fakültesi Dergisi. 4 (1), 73 - 88. 
Bahadır, E. ve Özdemir, A.Ş. (2016). Akademik başarı tahmininde yapay sinir ağları. 1. Baskı, Konya: Burç Yayınevi.

Ballabio D. \& Consonni V. (2013). "Classification tools in chemistry. Part 1: linear models. PLS-DA". Analytical methods. 5, 3790-3798.

Baş M. ve Çakmak Z. (2012). "Gri ilişkisel analiz ve lojistik regresyon analizi ile işletmelerde finansal başarısızlığın belirlenmesi ve bir uygulama”. Anadolu Üniversitesi Sosyal Bilimler Dergisi. 12 (3), 63-81.

Baykal A. (2006). "Veri madenciliği uygulamaları". Dicle Üniversitesi Ziya Gökalp Eğitim Fakültesi Dergisi. 7, 95-107.

Beaver W.H. (1966). "Financial ratios as predictors of failure". Journal of Accounting Research. 4 (3), 71-111.

Benli Y.K. (2005). "Bankalarda mali başarısızlı̆̆ın öngörülmesi lojistik regresyon ve yapay sinir ağı karşılaştırması”. Gazi Üniversitesi Endüstriyel Sanatlar Eğitim Fakültesi Dergisi. 16, 31-46.

Berk, N. (2010). Finansal yönetim. Genişletilmiş ve Güncelleştirilmiş 10. Baskı, İstanbul: Türkmen Kitabevi.

Bircan H. (2004). "Lojistik regresyon analizi: tıp verileri üzerine bir uygulama”. Kocaeli Üniversitesi Sosyal Bilimler Enstitüsü Dergisi. 2, 185-208.

Brédart X. (2014). "Bankruptcy prediction model: the case of the United States". International Journal of Economics and Finance. 6 (3), 1-7.

Brereton R.G. \& Lloyd G.R. (2014). "Partial least squares discriminant analysis: taking the magic away". Journal at Chemometrics. 28, 213-225.

Brigham, E.F. (1992). Fundamentals of financial management. 6th Edition, Fort Worth: Dryden.

Brigham, E.F. \& Houston, J.F. (2016). Finansal yönetimin temelleri. Dilek Demirhan (çev.). Nevzat Aypek (ed.). Ankara: Atlas Akademik Basım Yayın.

Bulut E. ve Alın A. (2009). "Kısmi en küçük kareler regresyon yöntemi algoritmalarından Nipals ve PLS-Kernel algoritmalarının karşılaştırılması ve bir uygulama”. Dokuz Eylül Üniversitesi İktisadi ve İdari Bilimler Fakültesi Dergisi. 24 (2), 127-138.

Bulut E. ve Alma Ö.G. (2012). "A performance assessment of model selection criteria when the number of objects is much larger than the number of variables in PLSR". European Journal of Applied Sciences. 4 (6), 257-264.

Bulut E. ve Eğrioğlu E. (2014). "A new partial least square method based on elman neural network". American Journal of Intelligent Systems. 4 (4), 154-158.

Bulut E. ve Çavuş G. (2015). "Liderlik, motivasyon ve ödüllendirme ilişkilerinin incelenmesinde kısmi en küçük kareler yol analizinin kullanılması”. Çankırı Karatekin Üniversitesi İktisadi ve İdari Bilimler Fakültesi Dergisi. 5 (2), 591-614.

Büker, S., Aşıkoğlu, R. ve Sevil, G. (1997). Finansal yönetim. Eskişehir: Anadolu Üniversitesi Basımevi.

Büker, S., Aşıkoğlu, R. ve Sevil, G. (2014). Finansal yönetim. 8. Bask1, Ankara: Sözkesen Matbaacilik.

Büyükarıkan U. ve Büyükarıkan B. (2014). "Bilişim sektöründe faaliyet gösteren firmaların finansal başarısızlık tahmin modelleriyle incelenmesi”. Akademik Bakış Dergisi. $46,160-172$. 
Cengiz D.T., Turanlı M., Kalkan S.B. ve Köse İ. (2015). “Türkiye'deki işletmelerin finansal başarısızlığının faktör analizi ve diskriminant analizi ile incelenmesi”. İstanbul Üniversitesi İktisat Fakültesi Ekonometri ve İstatistik Dergisi. 23, 62-79.

Ceylan, A. (2003). İsletmelerde finansal yönetim. 8. Basım, Bursa: Ekin.

Ceylan, A. ve Korkmaz, T. (2008). İşletmelerde finansal yönetim. Bursa: Ekin.

Charulatha G., Srinivasalu S., Maheswari O.U., Venugopal T. \& Giridharan L. (2017). "Evaluation of ground water quality contaminants using linear regression and artificial neural network models". Arabian Journal of Geosciences. 10 (128), 1-9.

Çelik, M.K. (2009). Finansal başarısızlık tahmin modellerinin IMKB'deki firmalar için karşılaştırmalı analizi. Yayımlanmamış doktora tezi, Karadeniz Teknik Üniversitesi Sosyal Bilimler Enstitüsü, Trabzon.

Çelik M.K. (2010). "Bankaların finansal başarısızlıklarının geleneksel ve yeni yöntemlerle öngörüsü”. Yönetim ve Ekonomi: Celal Bayar Üniversitesi İktisadi ve İdari Bilimler Fakültesi Dergisi. 17 (2), 129-143.

Çelik, U., Akçetin, E. ve Gök, M. (2017). RapidMiner ile uygulamalı veri madenciliği. 1. Baskı, Pusula: 2017.

Çokluk, Ö., Şekercioğlu, G. ve Büyüköztürk, Ş. (2014). Sosyal bilimler için çok değiş̧kenli istatistik SPSS ve LISREL uygulamaları. 3. Bask1, Ankara: Pegem Akademi.

Çolak C., Çolak M.C. ve Atıcı M.A. (2005). "Ateroskleroz’un tahmini için bir yapay sinir ağı”. Ankara Üniversitesi Tip Fakültesi Mecmuası. 58, 159-162.

Dağlı H. (1994). "İşletme başarısızlıkları ve alınması gerekli önlemler”. Verimlilik Dergisi. 1, MPM Yayınları: Ankara.

Deakin E.B. (1972). "A discriminant analysis of predictors of business failure". Journal of Accounting Research. 10 (1), 167-179.

Deakin E.B. (1976). "Distributions of financial accounting ratios: some empirical evidence". The Accounting Review. 51 (1), 90-96.

Delen D., Kuzey C. ve Uyar A. (2013). "Measuring firm performance using financial ratios: a decision tree approach". Expert Systems with Applications. 40 (10), 3970-3983.

Demirel, B. (2010). Veri madenciliğinde CHAID algoritmasının sosyal güvenlik kurumu veri tabanına uygulanması. Yayımlanmamış yüksek lisans tezi, Gazi Üniversitesi Fen Bilimleri Enstitüsü, Ankara.

Diakomihalis M. (2012). “The accuracy of Altman's models in predicting hotel bankruptcy”. International Journal of Accounting and Financial Reporting. 2 (2), 96-113.

Doğan B., Erol B. ve Buldu A. (2014). "Sigortacılık sektöründe müşteri ilişkileri yönetimi için birliktelik kuralı kullanılması”. Marmara Fen Bilimleri Dergisi. 3, 105-114.

Elmas, Ç. (2007). Yapay zeka uygulamaları. Ankara: Seçkin.

Emel G.G. ve Taşkın Ç. (2005). "Veri madenciliğinde karar ağaçları ve bir satı̧̧ analizi uygulaması”. Eskişehir Osmangazi Üniversitesi Sosyal Bilimler Dergisi. 6 (2), 221-239.

Ercan, M.K. ve Ban, Ü. (2005). Değere dayalı işletme finansı finansal yönetim. Ankara: Gazi Kitabevi.

Erpolat S. (2012). "Otomobil yetkili servislerinde birliktelik kurallarının belirlenmesinde apriori ve fp-growth algoritmalarının karşılaştırılması”. Anadolu Üniversitesi Sosyal Bilimler Dergisi. 12 (1), 151-166.

Fırat M. ve Güngör M. (2004). "Askı madde konsantrasyonu miktarının yapay sinir ağları ile belirlenmesi”. IMO Teknik Dergi. Yaz1 219, 326 -3282. 
Field, A. (2009). Discovering statistics using SPSS. 3rd Edition, Los Angeles: Sage.

Finansal raporlamaya ilişkin kavramsal çerçeve (2005). Erişim: 10.06.2018, http://www. kgk.gov.tr

Foster, G. (1986). Financial statement analysis. New Jersey: Prentice-Hall International.

Gamgam, H. ve Altunkaynak, B. (2015). SPSS uygulamalı regresyon analizi. Ankara: Seçkin.

Geng R., Bose I. \& Chen X. (2015). "Prediction of financial distress: an empirical study of listed Chinese companies using data mining". European Journal of Operational Research. 241 (1), 236-247.

Geyikçi U.B. ve Karaa İ.E. (2016). “Borsa İstanbul’a kayıtlı imalat işletmelerinin iflaslarının regresyon ve diskriminant yöntemleri ile tahminlenmesi”. Celal Bayar Üniversitesi Sosyal Bilimler Dergisi. 14 (2), 389-410.

Göktan, E. (1981). Muhasebe oranları yardımıyla ve diskriminant analiz tekniğini kullanarak endüstri işletmelerinin mali başarısızlığının tahmini üzerine ampirik bir araştırma. Yayımlanmamış doçentlik tezi.

Gräfer, H. (2001). Bilanzanalyse. 8. Auflage, Berlin: Verlag Neue Wirtschafts-Briefe.

Gülcan, N. (2011). Finansal oranlar yardımıyla işletmelerin finansal başarısızlıklarının tespit edilmesi; İMKB'de bir uygulama. Yayımlanmamıs yüksek lisans tezi, Süleyman Demirel Üniversitesi Sosyal Bilimler Enstitüsü, Isparta.

Güler İ. ve Übeyli E.D. (2006). “Çok katmanlı perseptron sinir ağları ile diyabet hastalığının teşhisi”. Gazi Üniversitesi Mühendislik Mimarlık Fakültesi Dergisi. 21 (2), 319-326.

Günay, S.G. (2014). İsletme finansının temelleri. Edirne: Paradigma Akademi Yayınları.

Hoare R. (2004). "Using CHAID for classification problems". New Zealand Association 2004 Conference. Wellington.

Horrigan J.P. (1983). "Methodological implications of non normally distributed financial ratios: a comment". Journal of Business Finance and Accounting. 10 (4), 683-689.

Iturriaga F.J.L \& Sanz I.P. (2015). "Bankruptcy visualization and prediction using neural networks: a study of U.S. commercial banks". Expert Systems with Applications. 42, 2857-2869.

İçerli M.Y. ve Akkaya G.C. (2006). "Finansal açıdan başarılı olan işletmelerle başarısız olan işletmeler arasında finansal oranlar yardımıyla farklılıkların tespiti”. Atatürk Üniversitesi İktisadi ve İdari Bilimler Dergisi. 20 (1), 413-421.

KAP (2017). İmalat Sanayii Şirketleri. Erişim Tarihi: 28.09.2017, https://www.kap.org.tr/ tr/Sektorler

KAP (2017). Finansal Tablolar. Erişim Tarihi: 30.09.2017, https://www.kap.org.tr/tr/

Kara, T. (2007). “Basın işletmelerinde likidite analizi: Hürriyet gazetesi örneği.” Marmara İletişim Dergisi. 12 (12), 151-158.

Karaali F.Ç. ve Ülengin F. (2008). "Yapay sinir ağları ve bilişsel haritalar kullanılarak işsizlik oranı öngörü çalışması". İTÜ Mühendislik Dergisi. 7(3), 15 - 26.

Karacan S. ve Savcı M. (2011). "Kriz dönemlerinde işletmelerin mali başarısızlık nedenleri”. Kocaeli Üniversitesi Sosyal Bilimler Enstitüsü Dergisi, 21 (1), 39-54.

Karapınar, A. ve Zaif, F.A. (2012). Uluslararası finansal raporlama standartları ile uyumlu finansal analiz. 2. Bask1, Ankara: Gazi Kitabevi. 
Kass, G.V. (1980). "An exploratory technique for investigating large quantities of categorical data”. Applied Statistics. 29 (2), 119-127.

Kaygın C.Y., Tazegül A. ve Yazarkan H. (2016). "İ̧sletmelerin finansal başarılı ve başarısız olma durumlarının veri madenciliği ve lojistik regresyon analizi ile tahmin edilebilirliğì". Ege Akademik Bakış. 16 (1), 147-159.

Kayri M. ve Boysan M. (2007). "Araştırmalarda chaid analizinin kullanımı ve baş etme stratejileri ile ilgili bir uygulama”. Ankara Üniversitesi Eğitim Bilimleri Fakültesi Dergisi. 40 (2), 133-149.

Khan U.E. (2016). "Bankruptcy prediction for financial sector of Pakistan: evaluation of logit and discriminant analysis approaches”. 6 (2), 210-220.

Kızıl, A., Fidan, M.M., Kızıl, C. ve Keskin, İ. (2013). Türkiye muhasebe ve finansal raporlama standartları. İstanbul: Der Yayınları.

Kolb, R.W. \& Rodriguez, R.J. (1996). Finansal yönetim. Ali İhsan Karacan (çev.). İlk Bask1, Ankara: Sermaye Piyasası Kurulu.

Korol T. (2013). "Early warning models against bankruptcy risk for Central European and Latin American enterprises”. Economic Modelling. 31, 22-30.

Koyuncugil, A.S. (2007). Borsa şirketlerinin sektörel risk profillerinin veri madenciliğiyle belirlenmesi. Sermaye Piyasası Kurulu Araştırma Raporu.

Koyuncugil A.S. ve Özgülbaş N. (2008). “İMKB’de işlem gören KOBİ’erin güçlü ve zayıf yönleri: CHAID karar ağacı uygulaması”. Dokuz Eylül Üniversitesi İktisadi ve İdari Bilimler Fakültesi Dergisi. 23 (1), 1-21.

Kulalı İ. (2016). "Altman Z-Skor modelinin BİST şirketlerinin finansal başarısızlık riskinin tahmin edilmesinde uygulanması". Uluslararası Yönetim İktisat ve İsletme Dergisi. 12 (27), 283-291.

Kurt Ç. ve Erdem O.A. (2012). "Öğrenci başarısını etkileyen faktörlerin veri madenciliği yöntemleriyle incelenmesi.” Politeknik Dergisi. 15 (2), 111-116.

Küçükkocaoğlu G., Benli Y.K. ve Küçüksözen C. (2007). "Finansal bilgi manipülasyonunun tespitinde yapay sinir ağı modelinin kullanımı”. IMKB Dergisi. 9 (36), 1-30.

Li B., Morris J. \& Martin E.B. (2002). "Model selection for partial least squares regression". Chemometrics and Intelligent Laboratory Systems. 64, 79-89.

Liang D., Lu C.C., Tsai C.F. \& Shih G.A. (2016). "Financial ratios and corporate governance indicators in bankruptcy prediciton: a comprehensive study". European Journal of Operational Research. 252 (2), 561-572.

Maimon, O. \& Rokach, L. (2010). Data mining and knowledge discovery handbook. 2th Edition, New York: Springer.

Mertler, C.A. \& Vannatta, R.A. (2005). Advanced and multivariate statistical methods: practical application and interpretation. 3rd Edition, Glendale CA: Pyrczak Publishing.

Morgan J. \& Sonquist J. (1963). "Problems in the analysis of survey data and a proposal". Journal of the American Statistical Association. 58 (302), 415-434.

Moshkovich H.M., Mechitov A.I. \& Olson D.L. (2002). "Rule induction in data mining: effect of ordinal scales". Expert Systems With Applications. 4 (22), 303-311.

Ohlson J.A. (1980). "Financial ratios and the probabilistic prediction of bankruptucy". Journal of Accounting Research. 18 (1), 109-131. 
Okka O. (2009). Analitik finansal yönetim. Ankara: Nobel.

Orhan U., Hekim M. ve Özer M. (2010). "EEG işaretlerinin çok-katmanlı algılayıcı yapay sinir ağı modeli ile sınıflandırılmasında ayrıklaştırma yaklaşımı”. 15. National Symposium on Biomedical Engineering. Antalya, 21-24 Nisan.

Özdamar, K. (2004). Paket programlar ile istatistiksel veri analizi 1. Eskişehir: Kaan.

Özdemir, F.S. (2011). Finansal başarısızlık ve finansal tablolara dayal tahmin yöntemleri. Ankara: Siyasal Kitabevi.

Özdemir F.S., Choi F.D.S. ve Bayazıtlı E. (2012). "Finansal başarısızlık tahminleri yönüyle UFRS ve bilginin ihtiyaca uygunluğu”. İSMMMO Mali Çözüm Dergisi. 112, 17-52.

Öztemel, E. (2012). Yapay sinir ağları. 3. Basım, İstanbul: Papatya.

Pektaş, A.O. (2013). SPSS ile veri madenciliği. 1. Bask1, İstanbul: Dikey Eksen.

Perridon, L., Steiner, M. \& Rathgeber, A. (2005). Finanzwirtschaft der Unternehmung. 8. Überarbeitete und Erweiterte Auflage, München: Verlag Franz Vahlen.

Poyraz E. ve Uçma T. (2006). “Türkiye'de faaliyet gösteren ihracatçı sektörlerin mali kriz ortamlarında finansal başarısızlıklarının Altman (Z-Score) modeli yardımıyla ölçülmesi”. Muhasebe ve Finansman Dergisi. 32, 127-136.

Rosipal, R. \& Krämer, N. (2006). "Overview and recent advances in partial least squares". C. Saunders, M. Grobelnik, S. Gunn \& J.S. Taylor (Eds.). Subspace, latent structure and feature selection (p. 34-51). Springer: Berlin.

Ross, S.A., Westerfield, R.W. \& Jaffe, J. (2001). Corporate finance. 6th Edition, New York: McGraw-Hill.

Rygielski C., Wang J.C. ve Yen D.C. (2002). "Data mining techniques for customer relationship management.” Technology in Society. 4 (24), 483-502.

Satıcı Ö., Akkuş Z. ve Alp A. (2009). "Tip fakültesi öğretim elemanlarının teknolojiye ilişkin tutumlarının CHAID analizi ile incelenmesi”. Dicle Tip Dergisi. 36(4), 267-274.

Schendera, C.F.G. (2014). Regressionsanalyse mit SPSS. 2. Korrigierte und Aktualisierte Auflage, München: De Gruyter Oldenbourg.

Schmid U. (2009). Entwicklung chemometrischer methoden für die klassifikation von bakterien mittels mikro - raman - spektroskopie. Dissertation, Fakultät für Lebenswissenschaften der Technischen Universität Carolo-Wilhelmina zu Braunschweig, Krumbach.

Selimoğlu S. ve Orhan A. (2015). "Finansal başarısızlığın oran analizi ve diskriminant analizi kullanılarak ölçümlenmesi: BİST’de işlem gören dokuma, giyim eşyası ve deri işletmeleri üzerine bir araştırma”. Muhasebe ve Finansman Dergisi. 66, 21-40.

Senbet, L.W. \& Seward, J.K. (1995). Financial distress, bankruptcy and reorganization. Jarrow, R.A., Maksimovic, V. \& Ziemba W.T. (Eds.). Handbooks in Operations Research and Management Science, Elsevier Science B.V.

Serrano-Cinca C. ve Gutiérrez-Nieto B. (2013). "Partial least square discriminant analysis for bankruptcy prediction”. Decision Support System. 54 (3), 1245-1255.

Shearer C. (2000). “The CRISP-DM model: the new blueprint for data mining”. Journal of Data Warehousing. 5 (4), 13-21.

Söylemez Y. ve Türkmen S.Y. (2017). "Yapay sinir ağları modeli ile finansal başarısızlık tahmini”. Finans Ekonomi ve Sosyal Araştırmalar Dergisi (FESA). 2 (4), 270-284.

Tabachnick, B.G. \& Fidell, L.S. (2015). Çok değişkenli istatistiklerin kullanımı. Mustafa Baloğlu (çev.). Mustafa Baloğlu (ed.). Ankara: Nobel. 
Terzi S. (2011). "Finansal rasyolar yardımıyla finansal başarısızlık tahmini: gıda sektöründe ampirik bir araştırma”. Çukurova Üniversitesi İİBF Dergisi. 15 (1), 1-18.

Tian Y., Wang Z., Han X., Hou H. \& Zheng R. (2014). “Comparative investigation of partial least squares discriminant analysis and support vector machines for geological cuttings identification using laser-induced breakdown spectroscopy". Spectrochimica Acta Part B. 102, 52-57.

TMS 1 (2005). Finansal tabloların sunuluşu. Erişim: 10.06.2018, http://www.kgk.gov.tr

Toraman C. ve Karaca C. (2016). "Kimya endüstrisinde faaliyet gösteren firmalar üzerinde mali başarısızlık tahmini: Borsa İstanbul'da bir uygulama”. Muhasebe ve Finansman Dergisi, 70, 111-128.

Türko M. (2002). Finansal yönetim. 2. Basım, İstanbul: Alfa Basım Yayım.

Uğur A. ve Kınacı A.C. (2006). "Yapay zeka teknikleri ve yapay sinir ağları kullanılarak web sayfalarının sinıflandırılması". XI. “Türkiye'de Internet” Konferansı Bildirileri. TOBB Ekonomi ve Teknoloji Üniversitesi, Ankara.

Uğurlu, S. (2016). “Lojistik regresyon analizi”. C.O. Güzeller (ed.). Herkes için çok değişkenli istatistik. (s.131-149). 1. Bask1, Ankara: Maya Akademi.

Uzun E. (2005). “İşletmelerde finansal başarısızlığın teorik olarak irdelenmesi”. Muhasebe ve Finansman Dergisi, 27, 158-168.

Ümit, A.Ö. ve Bulut E. (2013). “Türkiye'de işsizliği etkileyen faktörlerin kısmi en küçük kareler regresyon yöntemi ile analizi: 2005-2010 dönemi”. Dumlupınar Üniversitesi Sosyal Bilimler Dergisi. 37, 131-142.

Üngüren E. ve Doğan H. (2010). "Beş yıldızlı konaklama işletmelerinde çalışanların iş tatmin düzeylerinin CHAID analiz yöntemiyle değerlendirilmesi”. Cumhuriyet Üniversitesi İktisadi ve İdari Bilimler Dergisi. 11 (2), 39-52.

Van Horne, J.C. \& Wachowicz, J.M. (2008). Fundamentals of financial management. 13th Edition, London: Pearson.

Vatansever K. ve Aydın S. (2014). "Finansal başarısızlığın öngörülmesinde çok kriterli karar verme analizine dayalı bir araştırma”. Dumlupınar Üniversitesi Sosyal Bilimler Dergisi. 41, 163-176.

Vupa Ö. ve Alma Ö.G. (2008). "Regresyon analizinde kullanılan en küçük kareler ve en küçük medyan kareler yöntemlerinin karşılaştırılması”. Süleyman Demirel Üniversitesi Fen Edebiyat Fakültesi Fen Dergisi. 3 (2), 219-229.

Vural, B.B. (2007). Yapay sinir ağları ile finansal tahmin. Yayımlanmamış yüksek lisans tezi, Ankara Üniversitesi Sosyal Bilimler Enstitüsü, Ankara.

Wold H. (1975). "Soft modelling by latent variables: the non-linear iterative partial least squares (NIPALS) approach”. Journal of Applied Probability. 12 (S1), 117 - 142.

Wruck, K.H. (1990). "Financial distress: reorganization and organization efficiency". Journal of Financial Economics. 27 (2), 419-445.

Xiaosi X., Ying C. \& Haitao Z. (2011). “The comparison of enterprise bankruptcy forecasting method”. Journal of Applied Statistics. 38(2), 301-308.

Xu W., Xiao Z., Dang X., Yang D. \& Yang X. (2014). "Financial ratio selection for business failure prediction using soft set theory”. Knowledge Based-Systems. 63 (1), 59-67.

Yang G., Qiao S., Chen P., Ding Y. \& Tian D. (2015). "Rock and soil classification using PLS-DA and SVM combined with a laser-induced breakdown spectroscopy library". Plasma Science and Technology. 17 (8), 656-663. 


\section{Kaynakça}

Yılancı M., Yıldız B. ve Kiracı M. (2002). "Finansal başarısızlık ile çalışma sermayesi yönetimi arasındaki ilişki: SPK’ya tabi işletmelerde bir araştırma”. Muhasebe Bilim Dünyası Dergisi, 4 (4), 1-15.

Yıldırım, İ. (2006). İşletmelerde mali başarısızlıkların tahmininde erken uyarı sistemleri ve Türkiye için bir model önerisi. Yayımlanmamış yüksek lisans tezi, Gazi Üniversitesi Sosyal Bilimler Enstitüsü, Ankara.

Yılmaz H. ve Yıldıran M. (2015). "Borsada işlem gören işletmelerde mali başarısızlık tahmini: Altman Modeli’nin BIST uygulaması”. Aksaray Üniversitesi İktisadi ve İdari Bilimler Fakültesi Dergisi. 7 (3), 43-49.

Yücel E. (2017). Finansal sıkıntı, yeniden yapılandırma ve kurumsal yönetim. Ankara: Gazi Kitabevi.

Zırhlığlu G. (2011). "İnternet bağımlılı̆̆ının CHAID analizi ile incelenmesi: Van ili örneği”. Eğitimde ve Psikolojide Ölçme ve Değerlendirme Dergisi. 2 (2), 182-190.

Zinet, T.Ç. (2014). Iş̧letmelerin finansal başarısızlıklarının erken uyarı sistemleri ile tespiti ve BİST’te 2005-2013 dönemi bir uygulama. Yayımlanmamış yüksek lisans tezi, Yıldız Teknik Üniversitesi Sosyal Bilimler Enstitüsü, İstanbul.

2128 Sayılı Resmi Gazete, 2004 Sayılı İcra İflas Kanunu (http://www.mevzuat.gov.tr ). 